\title{
The Effects of Musical Fit on Consumers' Ability to Freely Recall Related Products
}

\author{
JOANNE P. S. YEOH ${ }^{[1]}$ \\ Music Department, University Putra Malaysia \\ ADRIAN C. NORTH \\ School of Life Sciences, Heriot Watt University, United Kingdom
}

\begin{abstract}
Previous studies have claimed that music can prime the selection of certain products and influence consumers' propensity to spend because it activates related knowledge of the world and subsequently raises the salience of certain products and behaviours associated with that music. The possibility that music can raise the salience of associated products has not been tested directly, however, and ought to manifest itself through enhanced ability to recall the products in question when associated music is played. Accordingly, this study investigated the impact of musical 'fit' on product recall. Participants were asked to list as many Malay and Indian food items as they could while listening to either Malay or Indian music. Among ethnically Chinese participants, more Malay food items were recalled when Malay music was played and more Indian food items were recalled when Indian music was played. Ethnically Malay and Indian participants were more likely to recall food from their own cultures, irrespective of the music played.
\end{abstract}

Submitted 2009 December 25; accepted 2010 January 16

KEYWORDS: music, consumers, recall

STUDIES concerning the effects of musical genre, rhythm, tempo, and modality on consumer behaviour have become increasingly common in the consumer behaviour literature over the past 20 years. For example, in perhaps the most regularly cited study in the field, Milliman (1982) found that fast tempo background music could significantly affect the pace of supermarket customers. Research concerning the notion of musical fit in commercial contexts is a relatively recent phenomenon. It refers to the process by which the associations customers have with a piece of music can either prime the amount that customers spend, depending on whether the music in question has connotations of affluence, or prime the selection of certain products that have similar associations. Although the published research discusses musical fit as though it were a universal phenomenon, at present all the research has been carried out in the West, and every study except one (North, Hargreaves, \& McKendrick, 1999) has focused specifically on the impact of Western classical music on the amount that customers are prepared to pay. This paper investigates the effect of musical fit in Malaysia, and rather than considering the amount that customers are prepared to pay, the present study concerns another possible manifestation of musical fit. Namely, that music with the same connotations as the product in question should prime recall of that product.

To date, research on musical fit has shown that consumers have the propensity to spend more when background music implies notions of affluence or wealth. For example, Areni and Kim (1993; see also North \& Hargreaves, 1998) showed that playing classical music in a wine cellar led to customers buying more expensive wine than when Top 40 music was playing. Similarly, North, Hargreaves, and McKendrick (1999) found that musical fit could prime the selection of certain products: customers were more likely to buy French wine than German wine when French music was played from a supermarket display, whilst German wines were selected when the display featured German music. Both these studies illustrate how music can prime consumers' choices. In the former study, the authors argued that classical music 'fitted' a stereotype involving notions such as 'expensive' and 'luxurious', which was why consumers bought the more expensive wine when classical music was being played. In the latter study, music primed or activated consumers' knowledge related to the products displayed. For example, German 
music primed knowledge associated with German wines and French music primed knowledge associated with French wines. If music that fits the product raises the salience of product attributes then this raised salience ought to also facilitate recall of the product.

It is interesting though that a similar argument can also be found commonly in the literature on the effects of rap and rock music on young people. Several researchers in this field have drawn explicitly on cognitive priming theory (e.g., Berkowitz \& Rogers, 1986) in arguing that exposing people to violent or sexist music videos should prime cognitions concerning related violent or sexist acts, such that the latter are subsequently regarded as more acceptable or are more likely to be displayed (e.g., Anderson, Carnagey, \& Eubanks, 2003; Hansen, 1989; Hansen \& Hansen, 1988, 1990, 1991; Hansen \& Krygowski, 1994; Johnson, Jackson, \& Gatto, 1995; and Ward, Hansbrough, \& Walker, 2005). Although carried out independently, this research itself mirrors studies within experimental aesthetics carried out during the same period indicating that music activates related knowledge structures, and that this should influence liking for it. Several studies have supported various manifestations of this approach such as, for example, Martindale's preference for prototypes model (see e.g., Hekkert \& van Wieringen, 1990; Martindale \& Moore, 1988; Martindale, Moore, \& Borkum, 1990). In short, studies within consumer psychology, media psychology, and experimental aesthetics suggest that music that fits a particular product or commercial behaviour is effectively a type of cognitive prime that activates superordinate knowledge of the world and therefore raises the salience of associated products. The increased level of activation of certain types of knowledge as a consequence of music also suggests the hypothesis of the present study, namely that musical fit should also increase the ability to recall the product in question.

To date, however, there have been only two attempts to investigate the ability of musical fit to facilitate recall specifically. Kellaris, Cox, and Cox (1993) note that 'musical-message fit' enhanced brand name and message recall when attention-gaining music was used. A similar study by North, Hargreaves, MacKenzie, and Law (2004) found that musical fit was able to prime recall of the specific brands and also the classes of products named in several radio adverts. However, the conclusions of these two studies may be limited by another factor addressed in the present study. North et al's participants, for example, were asked to respond to adverts for five fictional products with which they had obviously had no prior experience. The possibility remains that high levels of familiarity with the products in question operates as a ceiling effect that limits the ability of music to further activate knowledge of them and thus facilitate recall. In the present research, ethnically Chinese, Malay, and Indian participants were asked to recall Indian and Malay food products while Indian or Malay music played in the background. According to previous research on musical fit, these two types of music ought to lead to all participants being better able to recall the associated types of food. However, as a result of enculturation, ethnically Indian participants would arrive at the lab already far more familiar with Indian than Malay food, with the reverse applying to Malay participants. Would this high degree of familiarity eliminate any possibility for musical fit to further activate recall, which might be subsequently identified only in the ability of the ethnically Chinese participants to recall Indian and Malay foods?

Although, as noted earlier, only two previous studies have addressed the ability of musical fit to promote recall, a few others have addressed music and memory from different perspectives. These studies provide only mixed results on the efficacy of music as a memory cue. Haley, Richardson, and Baldwin (1984) note that the most frequent method for eliciting recall of advertising from consumers is the use of verbal cues, and suggest that it may be impossible to retrieve the effects of nonverbal advert elements such as music, voice quality, and visual imagery except by focusing respondents on the stimulus of interest. Some support for the positive effects of music may be found in copy testing research that showed a tendency for television advertising containing music to be remembered better than ads without music (see Stewart \& Furse, 1986; Stewart, Farmer, \& Stannard, 1990; Edell \& Keller, 1989; Yalch, 1991; Tom, 1990; and Oakes, 2007). However, this was not found by McEwen and Leavitt (1976), and similar research using radio advertising reported no positive effects (Radio Recall Research, 1981; Seawall \& Sarel, 1986). To further complicate matters, laboratory experiments have frequently revealed negative recall effects of incorporating music in advertising (e.g. Anand \& Sternthal, 1990; Park \& Young, 1986; Wheatley \& Brooker, 1988; and MacInnis \& Park, 1991).

The present study investigated whether musical fit could facilitate recall of culturally-associated food products among participants from three ethnic groups. While Malay and Indian music played in the background, Malay, Indian, and Chinese participants were requested to freely recall as many Malay (e.g., nasi lemak, kuih lapis) and Indian (e.g., muruku, putu mayam) food items as they could. It was predicted that participants who heard Malay music would be better able to recall more Malay food items while 
participants who heard Indian music would be better able to recall more Indian food items. However, it was also predicted that this effect would be much stronger among ethnically Chinese than among ethnically Malay and Indian participants as the latter two groups would be particularly disposed to recall food from their own cultures, irrespective of the music playing in the background.

\section{METHOD}

\section{Participants}

Malaysia comprises three major, distinct ethnic groups, namely Malays, Indians, and Chinese, each of which has a distinct culture which includes particular cuisines. Participants were 144 students from University Putra Malaysia, divided into two groups of 72 participants each. Each group comprised 24 Malays (12 males, 12 females), 24 Chinese (12 males, 12 females), and 24 Indians (12 males, 12 females). All participants were aged $16-35$ years $($ mean $=21.67, S D=2.77)$.

\section{Materials and Design}

The research used a within subjects design in which the two groups, each comprising Malay, Indian, and Chinese participants, were played either Malay music or Indian music. The Malay and Indian musical pieces employed were examples of instrumental 'classical' music, distinct enough to be readily-identified as Malay or Indian respectively by all 20 participants in a short pilot study. The Malay music was taken from the CD Muzik Tarian Malaysia. The specific track used was Serampang Pantai. The music was of a moderate tempo which made use of typical Malay instruments such as the serunai, and rebana. The track was looped for 30 minutes. The Indian music was taken from the CD Master Pieces by $\mathrm{Dr} N$. Rajam. The track used here was Raga Deshi, a piece of somewhat moderate speed, and highlighted the use of the sitar and tabla, and this track itself lasts for 29 minutes 55 seconds. The music was played through a pair of headphones (AVF HM560) attached to a laptop computer. A mixed design was employed in which participants from the three ethnic groups were played either Malay or Indian music while attempting to list as many Malay and Indian food items as they could.

\section{Procedure}

Participants were tested individually between $12.00 \mathrm{pm}$ and $4.00 \mathrm{pm}$ over three weeks. Participants were told they could take as long as they liked to nominate the food items, and should stop only when they were certain that they could not recall any more Malay or Indian food items. Testing was conducted via one-onone sessions in a quiet room on campus.

\section{RESULTS}

A mixed ANOVA was carried out to determine whether the number of Indian and Malay foods recalled differed depending on the type of music played and participants' ethnicity. The type of food $\mathrm{x}$ music $\mathrm{x}$ ethnicity interaction was significant $(F(2,138)=3.41, p=.036)$. The mean number of food items recalled is cross-tabulated by music and participant ethnicity in Table 1 . This indicates that the Chinese participants had a strong tendency to recall more Malay than Indian food items when Malay music was played; and more Indian than Malay food items when Indian music was played. However there were no effects of musical fit on recall among the ethnically Malay and Indian participants: the ethnic Malays recalled more Malay food items whatever music was played, and the ethnic Indians recalled more Indian food items whatever music was played. 


\begin{tabular}{|c|c|c|c|c|}
\hline \multicolumn{5}{|c|}{ Malay music } \\
\hline Ethnicity & $\begin{array}{c}\text { Malay food } \\
\text { items }\end{array}$ & $S D$ & $\begin{array}{c}\text { Indian food } \\
\text { items }\end{array}$ & $S D$ \\
\hline Chinese & 5.12 & 2.49 & 3.96 & 2.03 \\
\hline Malay & 7.87 & 2.95 & 4.12 & 1.68 \\
\hline Indian & 7.00 & 3.16 & 7.96 & 2.91 \\
\hline \multicolumn{5}{|c|}{ Indian music } \\
\hline Ethnicity & $\begin{array}{c}\text { Malay food } \\
\text { items }\end{array}$ & $S D$ & $\begin{array}{c}\text { Indian food } \\
\text { items }\end{array}$ & $S D$ \\
\hline Chinese & 4.67 & 2.08 & 5.54 & 2.43 \\
\hline Malay & 9.50 & 4.17 & 4.92 & 2.45 \\
\hline Indian & 10.29 & 5.01 & 12.38 & 6.18 \\
\hline
\end{tabular}

Note: $S D=$ standard deviation

Table 1. Mean number of Malay and Indian food items recalled by participants from Chinese, Malay, and Indian ethnic groups when listening to Malay or Indian music.

\section{DISCUSSION}

Previous studies concerning musical fit have indicated that music can increase the amount consumers spend or the items that they select. In addition, this study demonstrates that musical fit is able to prime consumers' memory for particular related items. This study supports the largely untested claim of previous studies that musical fit operates by activating knowledge of the world and raising the salience of associated products. Perhaps more importantly, the results here also indicate a clear limitation to the scope of this effect, namely that it may occur only when participants are not already very familiar with the products in question: musical fit effects were observed only in the ethnically Chinese participants, who otherwise had no a priori reason to be particularly familiar with one type of food over the other. Ethnically Malay and Indian participants did not produce data consistent with the notion of music making certain products more salient than others, suggesting that enculturation may impose a form of ceiling effect on the ability of musical fit to increase the salience of cultural products.

These findings may have implications for retailing and advertising alike. Department stores and supermarket may, for example, use music to cue shoppers to consider certain product categories or to visit certain sections of the store which sell those products. With regard to advertising, there is of course typically a delay between exposure to advertising and actual purchasing, and musical fit might be one means by which advertisers can ensure that their product is recalled during the intervening period. Similarly, it might be possible for an advertiser to use musical fit to draw consumers' attention to one particular aspect of a product that gives it an advantage over an otherwise similar competing brand. On a slightly more pessimistic note, we should note that there are also several possible limitations to these effects. For example, if consumers have no prior experience of the music used then the chances are they may not derive the appropriate communicative intent from that music. Rather, retailers and advertisers should employ either very well-known pieces of unambiguous music or rely on the stereotypes associated with entire musical styles. Furthermore, it remains to be determined whether too great a degree of musical fit could instead lead to the advert or retail environment in question seeming somewhat hackneyed. For instance, the use of very literal lyrics (e.g., Aretha Franklin's You make me feel like a natural woman in an advert for shampoo) might not appeal to a market segment that perceives itself as sophisticated. Along similar lines, the present research did not test the possibility that high degrees of incongruity between products and music may also prime recall of the former, by for instance causing deeper processing (see Heckler \& Childers, 1992; Houston, Childers, \& Heckler, 1987). We might also note that while such a possibility exists from a theoretical perspective, such effects should not be attempted by practitioners, given 
existing evidence which shows that high levels of musical incongruity are disliked by people in commercial (North \& Hargreaves, 1996a) and other (North \& Hargreaves, 1996b) contexts.

Musical fit is undoubtedly a multi-faceted concept. For instance, the extent to which a given piece of music fits (or does not fit) with a particular product might be determined by its tempo, intensity, instrumentation, mode, and articulation, among several other possible candidate variables. Indeed, the extent to which we should even attempt to define musical fit in terms of objectively-measurable aspects of musical structure reflects a broader debate that has taken place within the field of aesthetics over the past few decades. In that field, several authors have addressed the very well-known absolutist versus referentialist approach to emotional responses to music. At the risk of over-generalising, proponents of the former approach argue that musical meaning resides within musical structure itself, whereas proponents of the latter argue that musical meaning resides in the associations that a given listener has with the piece in question. Similarly, several studies of musical preference have addressed the extent to which this might be determined by the complexity of the music in question. Whereas some (e.g., Berlyne, 1974) have argued that this concept can be measured by objective, mathematical means, others (e.g., Heyduk, 1975; North \& Hargreaves, 1995) have argued that it is the complexity of a piece of music, as experienced by the listener, that is crucial in determining preference, rather than any objective, mathematical measure.

Similarly, since a single piece of music represented each of the musical styles employed in the present research it is impossible to say whether the present results are attributable to musical fit effects associated with solely the specific pieces of music employed or instead to musical fit effects associated with the musical styles that the pieces of music represented (or both). Future research might address this by employing several pieces to represent each style and then determining whether the effects of all the pieces within the style are similar (indicating an effect at the level of the style per se) or dissimilar (indicating that the effect operates at the level of specific pieces of music). Such issues of course go beyond the hypothesis of the present research, namely that musical fit should prime memory, but do suggest clear opportunities for future work.

\section{NOTES}

[1] Corresponding e-mail address: joanneyeoh@gmail.com

\section{REFERENCES}

Anand, P., \& Sternthal, B. (1990). Ease of message processing as a moderation of repletion effects in advertising. Journal of Marketing Research, 27, 345-353.

Anderson, C.A., Carnagey, N.L., \& Eubanks, J. (2003). Exposure to violent media: The effects of songs with violent lyrics on aggressive thoughts and feelings. Journal of Personality and Social Psychology, 84, 960-971.

Areni, C.S. \& Kim, D. (1993). The influence of background music on shopping behavior: Classical versus top-forty music in a wine store. Advances in Consumer Research, 20, 336-340.

Berkowitz, L. \& Rogers, K.H. (1986). A priming effect analysis of media influences. In J. Bryant and D. Zillmann (Eds.), Perspectives on media effects (pp. 57-81). Hillsdale: Erlbaum.

Berlyne, D.E. (1974). The new experimental aesthetics. In D.E. Berlyne (Ed.). Studies in the new experimental aesthetics: Steps toward an objective psychology of aesthetic appreciation. New York: Halsted Press.

Edell, J. \& Keller, K.L. (1989). The information processing of coordinated media campaigns. Journal of Marketing Research, 26(2), 149-163. 
Haley, R.I., Richardson, J., \& Baldwin, B.M. (1984). The effects of nonverbal communications in television advertising. Journal of Advertising Research, 24(4), 12-18.

Hansen, C.H. (1989). Priming sex-role stereotypic event schemas with rock music videos: Effects on impression favorability, trait inferences, and recall of a subsequent male-female interaction. Basic and Applied Social Psychology, 10, 371-391.

Hansen, C.H. \& Hansen, R.D. (1988). How rock music videos can change what is seen when boy meets girl: Priming stereotypic appraisal of social interactions. Sex Roles, 19, 287-316.

Hansen, C.H. \& Hansen, R.D. (1990). Rock music videos and antisocial behavior. Basic and Applied Social Psychology, 11, 357-369.

Hansen, C.H. \& Hansen, R.D. (1991). Schematic information processing of heavy metal lyrics. Communication Research, 18, 373-411.

Hansen, C.H. \& Krygowski, W. (1994). Arousal-augmented priming effects: Rock music videos and sex object schemas. Communication Research, 18, 24-47.

Heckler, S.E. \& Childers, T.L. (1992). The role of expectancy and relevancy in memory for verbal and visual information: What is incongruency? Journal of Consumer Research, 18, 475-492.

Hekkert, P. \& van Wieringen, P.C.W. (1990). Complexity and prototypicality as determinants of the appraisal of cubist paintings. British Journal of Psychology, 81, 483-495.

Heyduk, R.G. (1975). Rated preference for musical composition as it relates to complexity and exposure frequency. Perception and Psychophysics, 17, 84-91.

Houston, M.J., Childers, T.L., \& Heckler, S.E. (1987). Picture-word consistency and elaborative processing of advertisements. Journal of Marketing Research, 24, 359-369.

Johnson, J.D., Jackson, L.A., \& Gatto, L. (1995). Violent attitudes and deferred academic aspirations: deleterious effects of exposure to rap music. Basic and Applied Social Psychology, 16, 27-41.

Kellaris, J.J, Cox, A.D., \& Cox, D. (1993). The effects of background music on ad processing: A contingency explanation. Journal of Marketing, 57(4), 114-125.

MacInnis, D.J., \& Park, C.W. (1991). The differential role of characteristics of music on high-and lowinvolvement consumers' processing of ads. Journal of Consumer Research, 18(2), 161-173.

Martindale, C. \& Moore, K, (1988). Priming, prototypicality, and preference. Journal of Experimental Psychology: Human Perception and Performance, 14, 661-670.

Martindale, C., Moore, K., \& Borkum, J. (1990). Aesthetic preference: Anomalous findings for Berlyne's psychobiological theory. American Journal of Psychology, 103, 53-80.

McEwen, J., \& Leavitt, C. (1976). A way to describe TV commercials. Journal of Advertising Research, 16, 35-39.

Milliman, R.E. (1986). The influence of background music on the behavior of restaurant patrons. Journal of Consumer Research, 13(9), 286-289.

North, A.C. \& Hargreaves, D.J. (1995). Subjective complexity, familiarity, and liking for popular music. Psychomusicology, 14, 77-93. 
North, A.C., \& Hargreaves, D.J. (1996a). The effects of music on responses to a dining area. Journal of Environmental Psychology, 16, 55-64.

North, A.C., \& Hargreaves, D.J. (1996b). Responses to music in aerobic exercise and yogic relaxation classes. British Journal of Psychology, 87, 535-547.

North, A.C. \& Hargreaves, D.J. (1998). The effect of music on atmosphere and purchase intentions in a cafeteria. Journal of Applied Social Psychology, 28, 2254-2273.

North, A.C., Hargreaves, D.J., \& McKendrick, J. (1999). The effect of music on in-store wine selections. Journal of Applied Psychology, 84, 271-276.

North, A.C., Hargreaves, D.J., MacKenzie, L., \& Law, R. (2004). The effects of musical and voice 'fit' on responses to adverts. Journal of Applied Social Psychology, 34, 1675-1708.

Oakes, S. (2007). Evaluating empirical research into music in advertising: A congruity perspective. Journal of Advertising Research, 47, 38-50.

Park, C.W., \& Young, S.M. (1986). Consumer response to television commercials: the impact of involvement and background music on brand attitude formation. Journal of Marketing Research, 23(1), 1124.

Radio Recall Research. (1981). Characteristics leading to significant differences in recall rates. Holndel, NJ: Radio Research, Inc.

Sewall, M.A., \& Sarel, D. (1986). Characteristics of radio commercials and their recall effectiveness. Journal of Marketing, 50, 52-60.

Stewart, D.W., \& Furse, D.H. (1986). Effective Television Advertising: A study of 1000 commercials. Lexington, MA: Lexington Books.

Stewart, D.W., Farmer, K.M., \& Stannard, C.I. (1990). Music as a recognition cue in advertising-tracking studies. Journal of Advertising Research, 30(4), 39-48.

Tom, V. (1990). Marketing with music. Journal of Consumer Marketing, 7(2), 49-53.

Ward, L.M., Hansbrough, E., \& Walker, E. (2005). Contributions of music video exposure to black adolescents' gender and sexual schemas. Journal of Adolescent Research, 20, 143-166.

Wheatle, J.J., \& Brooker, G. (1988). Music and spokesperson effects in radio advertising. Unpublished manuscript, University of Washington, School of Business Administration.

Yalch, R.F. (1991). Memory in a jingle jungle: Music as a mnemonic device in communicating advertising slogans. Journal of Applied Psychology, 76(2), 268-275. 